\title{
Laser interstitial thermotherapy (LITT) for the treatment of tumors of the brain and spine: a brief review
}

\author{
Clark Chen ${ }^{1} \cdot \operatorname{lan}$ Lee $^{2} \cdot$ Claudio Tatsui $^{3} \cdot$ Theresa Elder $^{4} \cdot$ Andrew E. Sloan $^{4,5}$ (i)
}

Received: 28 April 2020 / Accepted: 15 October 2020

(c) The Author(s) 2021

\begin{abstract}
Introduction Laser Interstitial Thermotherapy (LITT; also known as Stereotactic Laser Ablation or SLA), is a minimally invasive treatment modality that has recently gained prominence in the treatment of malignant primary and metastatic brain tumors and radiation necrosis and studies for treatment of spinal metastasis has recently been reported.

Methods Here we provide a brief literature review of the various contemporary uses for LITT and their reported outcomes. Results Historically, the primary indication for LITT has been for the treatment of recurrent glioblastoma (GBM). However, indications have continued to expand and now include gliomas of different grades, brain metastasis (BM), radiation necrosis $(\mathrm{RN})$, other types of brain tumors as well as spine metastasis. LITT is emerging as a safe, reliable, minimally invasive clinical approach, particularly for deep seated, focal malignant brain tumors and radiation necrosis. The role of LITT for treatment of other types of tumors of the brain and for spine tumors appears to be evolving at a small number of centers. While the technology appears to be safe and increasingly utilized, there have been few prospective clinical trials and most published studies combine different pathologies in the same report.

Conclusion Well-designed prospective trials will be required to firmly establish the role of LITT in the treatment of lesions of the brain and spine.
\end{abstract}

Keywords LITT $\cdot$ Laser interstitial thermotherapy $\cdot$ SLA $\cdot$ Stereotactic laser ablation · Glioma $\cdot$ Brain metastasis · Radiation necrosis $\cdot$ Meningioma $\cdot$ Spinal metastasis

\section{Introduction}

Laser Interstitial Thermotherapy (LITT; also known as Stereotactic Laser Ablation or SLA) is a minimally invasive treatment modality that has recently gained prominence in the treatment of malignant brain tumors [1-15]. Historically, the primary indication for LITT has been for the treatment of recurrent glioblastoma (GBM). However, indications have continued to expand and now include gliomas of different grades, brain metastasis $(\mathrm{BM})$, radiation necrosis $(\mathrm{RN})$ as

\footnotetext{
Andrew E. Sloan

Andrew.Sloan@UHHospitals.org

University of Minnesotta, Minneapolis, USA

Henry Ford Hospitals, Detroit, USA

MD Anderson Cancer Center, Houston, USA

4 Seidman Cancer Center, University Hospitals, Shaker Heights, USA

5 Case Comprehensive Cancer Center, Cleveland, USA
}

well as spine tumors $[1-14,16,17]$. There are also small numbers of other tumor types which have been treated with LITT. This paper serves as a brief review of these topics with conclusions in each section.

Thermal ablation using cryoablation, radiofrequency, ultrasound and laser has a long tradition of efficacy in many tumor types including brain tumors $[15,18,19]$. However, while laser has long been utilized for open surgery, the earliest cases of LITT for brain tumors were reported in 1983 [20]. The efficacy of early LITT was highly variable, performed with different, unique platforms at a small number of institutions, and thus limited to sites with clinical interest and technological support [12, 21-23]. After 2006, three technological innovations led to commercialization of LITT which in turn led to increased adoption for tumors and epilepsy: the development of MRI compatible, cooled probes; reproducible MRI thermometry; and software that could integrate the findings of repeated thermometry to identify cumulative thermal damage of several individual LITT treatments. The two currently commercially available 
LITT platforms are the "Visualase" system approved by the FDA in 2009 after a phase I study in 4 patients with brain metastasis, and the Monteris NeuroBlate Platform, which was first approved by the FDA in 2013 after a first in man trial in 10 patients with unresectable recurrent glioblastomas $[11,24]$. The features of these platforms have been described previously [25-27].

\section{Treatment of low grade gliomas (WHO grade I-II)}

Eighteen studies and case reports have described treatment of 98 patients undergoing LITT therapy for low grade gliomas (Table 1) [21, 28-38]. The majority of tumors were less than $35 \mathrm{~mm}$ in diameter and were considered unresectable because of location within eloquent brain or due to a perceived high risk of conventional open surgery. LITT was usually used as the primary mode of treatment and not followed by adjuvant therapy. In the overwhelming majority, tumors were in areas of eloquence or very high surgical risk [29, 31, 33, 34, 39-42]. In general, the use of LITT in treating low grade (WHO I-II) glioma appears to be well tolerated without permanent neurological deficits. The majority of tumors were stable, or demonstrated partial response. One study provided mean values for time to progression and survival of 16 and 34 months, respectively [21]. No prospective clinical trials have been reported.

\section{High grade gliomas (WHO grade III-IV)- including recurrent GBMs}

Nineteen studies highlighted experience with LITT of highgrade gliomas (WHO grade III and IV), reporting 252 cases (Table 2) [9, 21, 22, 24, 25, 27, 30, 32, 33, 43-46]. The age of patients varied from 24 to 78 years. All treated tumors were $<50 \mathrm{~mm}$ in diameter. LITT was mainly utilized for management of residual or recurrent neoplasms, when other treatment options had been exhausted. In general, thermal therapy was well tolerated. The most common complications were seizures as well as complications typical of this population of patients with malignant brain tumors and limited mobility including deep venous thrombosis, and pulmonary embolism. These complications were encountered, on average, in $3.5 \%, 4.7 \%$ and $2.4 \%$ of cases, respectively, with slightly higher risk in patients with recurrent tumors [21, 24, 33, 44-46]. Moderate perilesional brain edema after surgery was common [24, 32, 43, 46]. Transient postoperative neurological decline was occasionally noted, whereas permanent deficit was only encountered in $0-10 \%$ of patients (in average, $4.8 \%)[22,25,33,47]$. The risk of deficit was associated with early use of the technology, as well as treatment of large and deep seated or eloquent lesions.
Length of hospital stay after LITT for recurrent GBM (rGBM) was shorter in comparison to tumor resection [48, 49]. During follow-up, tumors usually demonstrated volume reduction [24, 32, 33, 43]. Several clinical series also demonstrated extended survival (median, 9.0-11.2 months) after LITT in patients with rGBM refractory to other treatment and not suitable for re-resection, which was beneficial in comparison to best palliative care [21, 22, 24, 25, 27, 46].

Another challenge has been tumor volume. Most of the lesions treated in the literature, and the majority of the patients with the best outcomes, are those with volumes of less than $10 \mathrm{~cm}^{3}$ (which corresponds to a radius of $1.33 \mathrm{~cm}$ ) [1,5]. This has been attributed to the observation that larger tumors typically cause more swelling which is poorly tolerated. Wright et al. demonstrated that LITT can be combined with a minicraniotomy and trans-sulcal, trans-tubular approach which addresses the challenge of post-treatment swelling in patients with large, difficult to access large [1]. The authors noted that in this subgroup of patients, minimally invasive LITT combined with a small craniotomy using a tubular retractor system facilitated a radical resection required to achieve survival advantage in such patients without the need for a larger craniotomy. They noted that LITT changed the consistency of the tumor, devascularizing it and making it more "suckable" and thus more easily and safely removable. Median survival in this study of 10 patients with median age of 65 was more than 16 months, with PFS of 9.3 months [1]. Another group demonstrated that LITT induces a transient breakdown of the peritumoral blood-tumor barrier which has potential to improve drug delivery to intracranial tumors [50]. Several trials assessing the utility of LITT to augment drug delivery have been proposed and some are underway.

The two largest case series of LITT for GBM also demonstrated a longer survival time in patients using LITT when no other therapeutic options were available to the patient except for best palliative care. The first in man trial of LITT for inoperable rGBM demonstrated a median survival of 10.5 months after LITT compared to the expected 3-5 month median survival with best conventional care $(n=10$ patients) which was replicated in another series of four cases [24, 27]. However, it should also be noted that recurrent GBM amenable to treatment with LITT are highly selective subpopulation of GBM with unifocal tumors less than $5 \mathrm{~cm}$ in diameter, and thus not necessarily generalizable to many historical controls. In general, LITT has been well tolerated although temporary and permanent injuries have also been observed after LITT. Two studies, totaling 32 patients, have examined the length of hospital stay (LOS) in LITT versus open surgical resection scenarios, and both proved a shorter length in favor of LITT [22, 25]. While only three of the published studies were prospective clinical trials, three ongoing studies examine the potential of LITT to potentiate chemotherapy or immunotherapy $[11,14$, 24, 51-53]. 


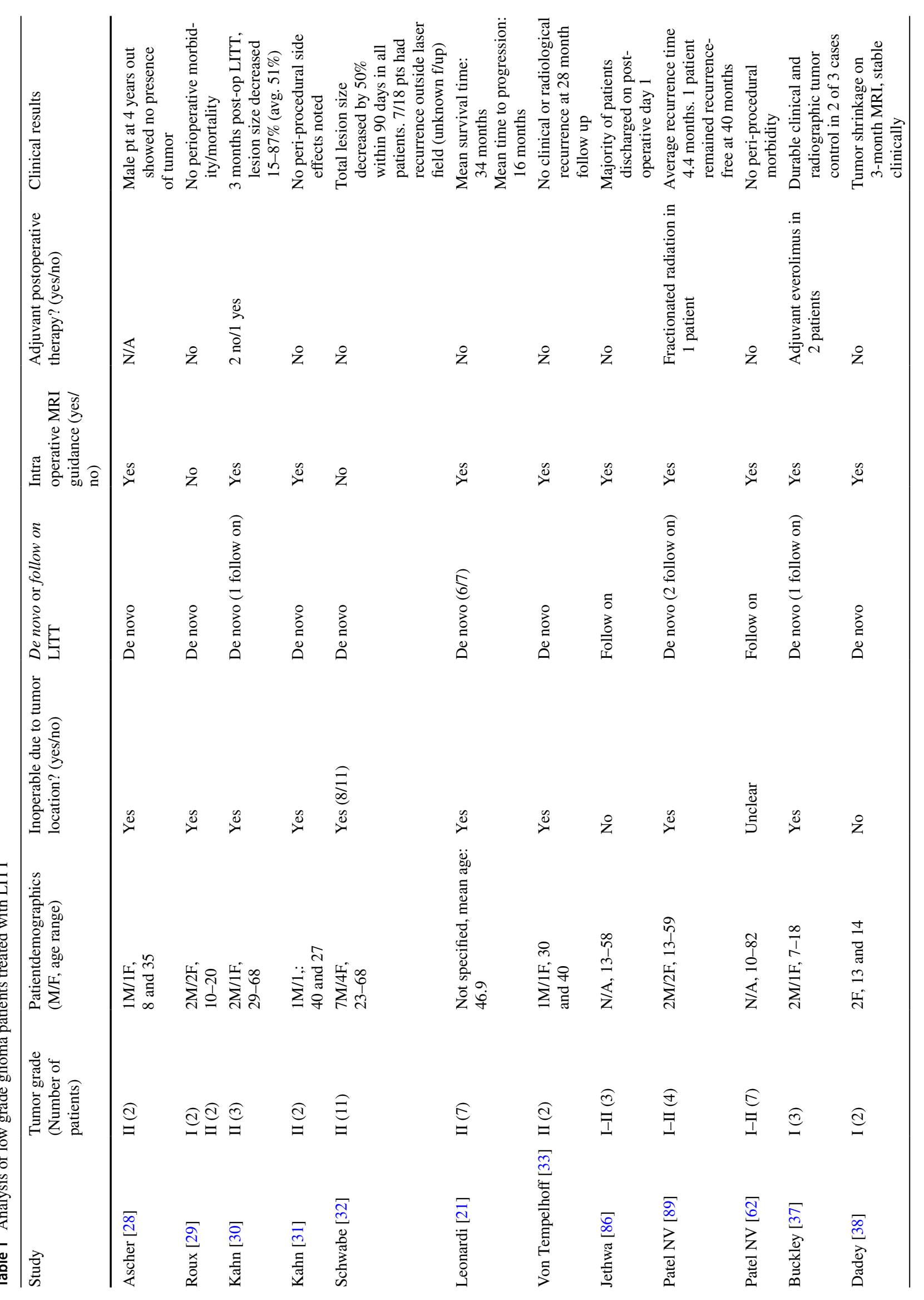




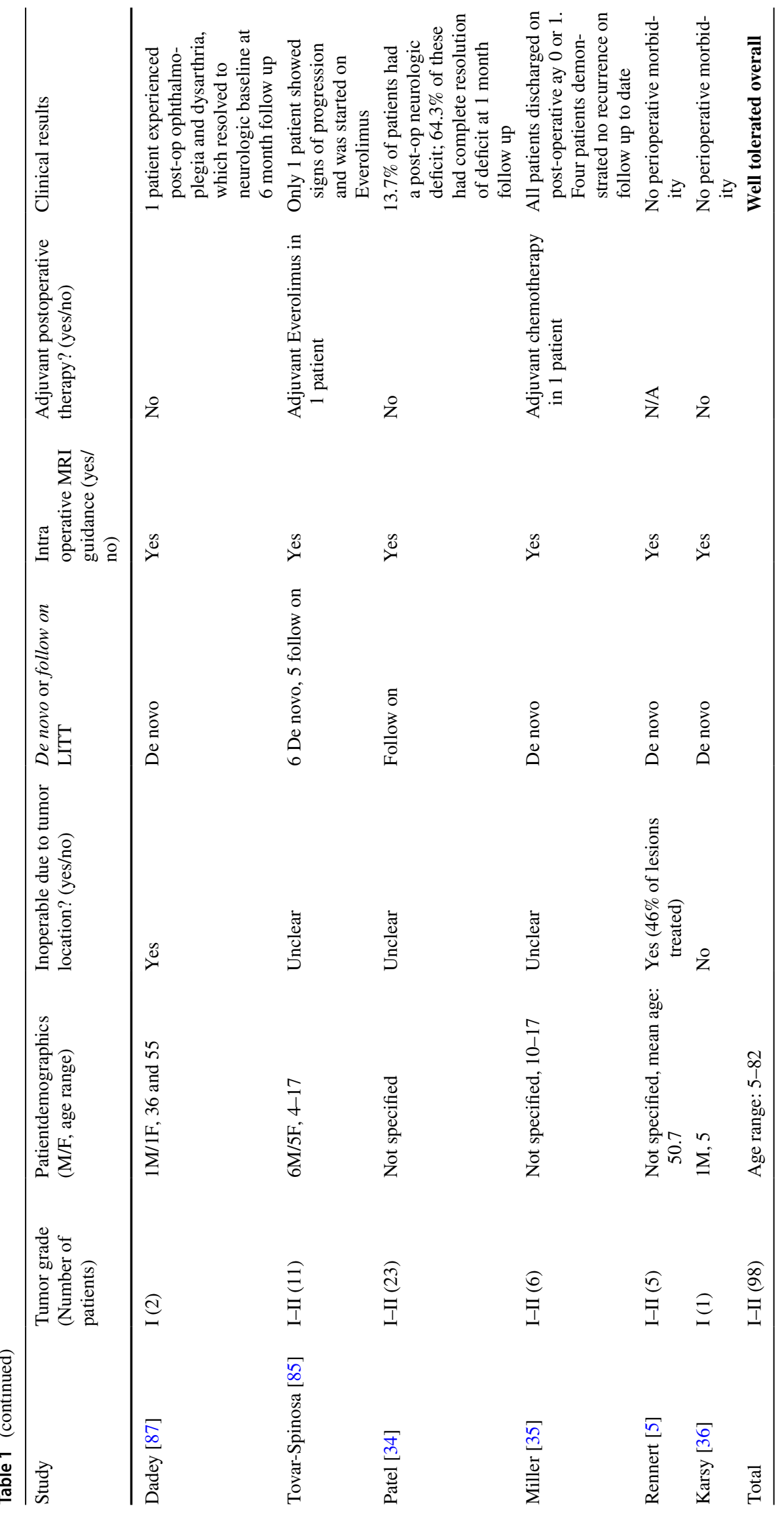




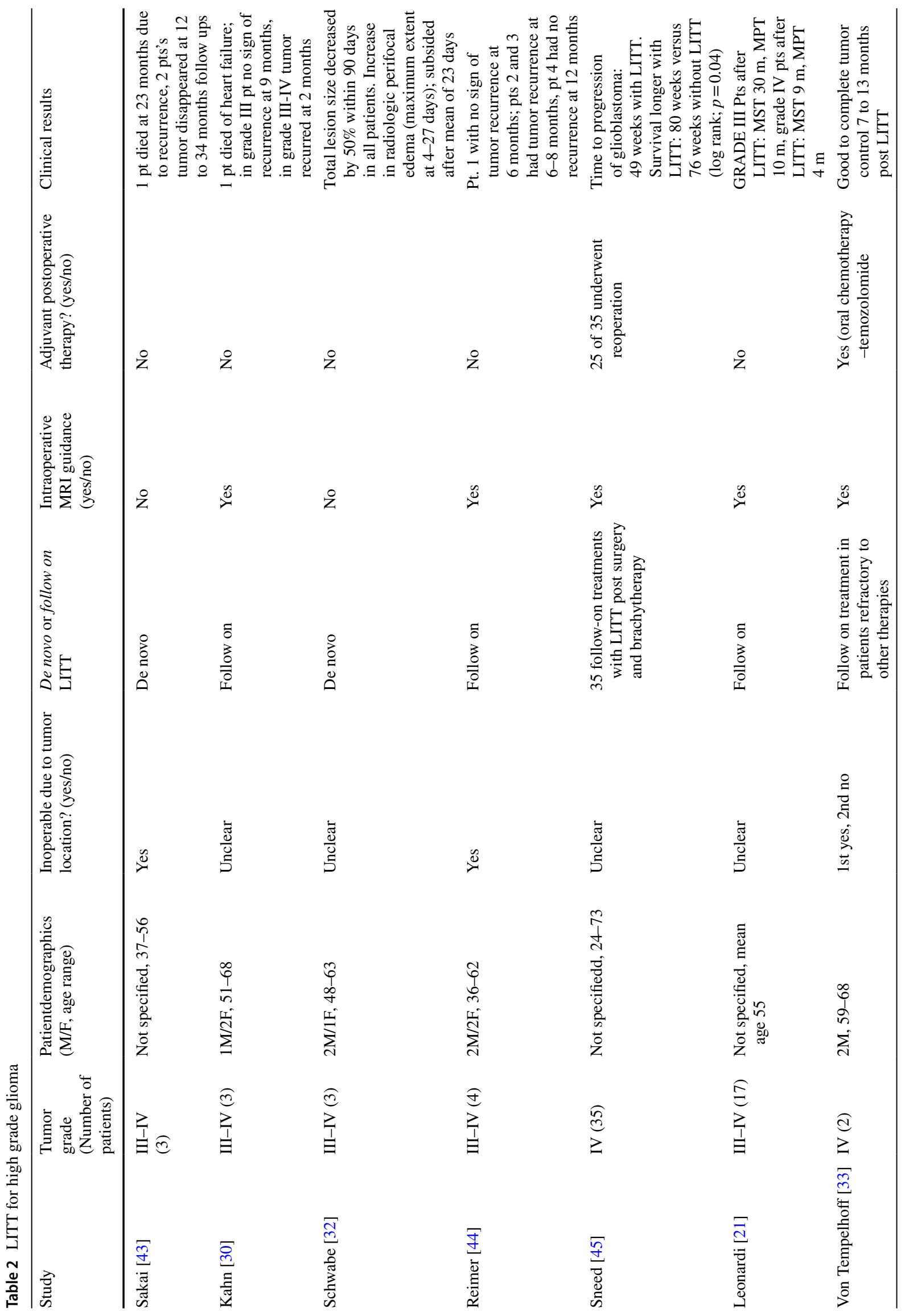




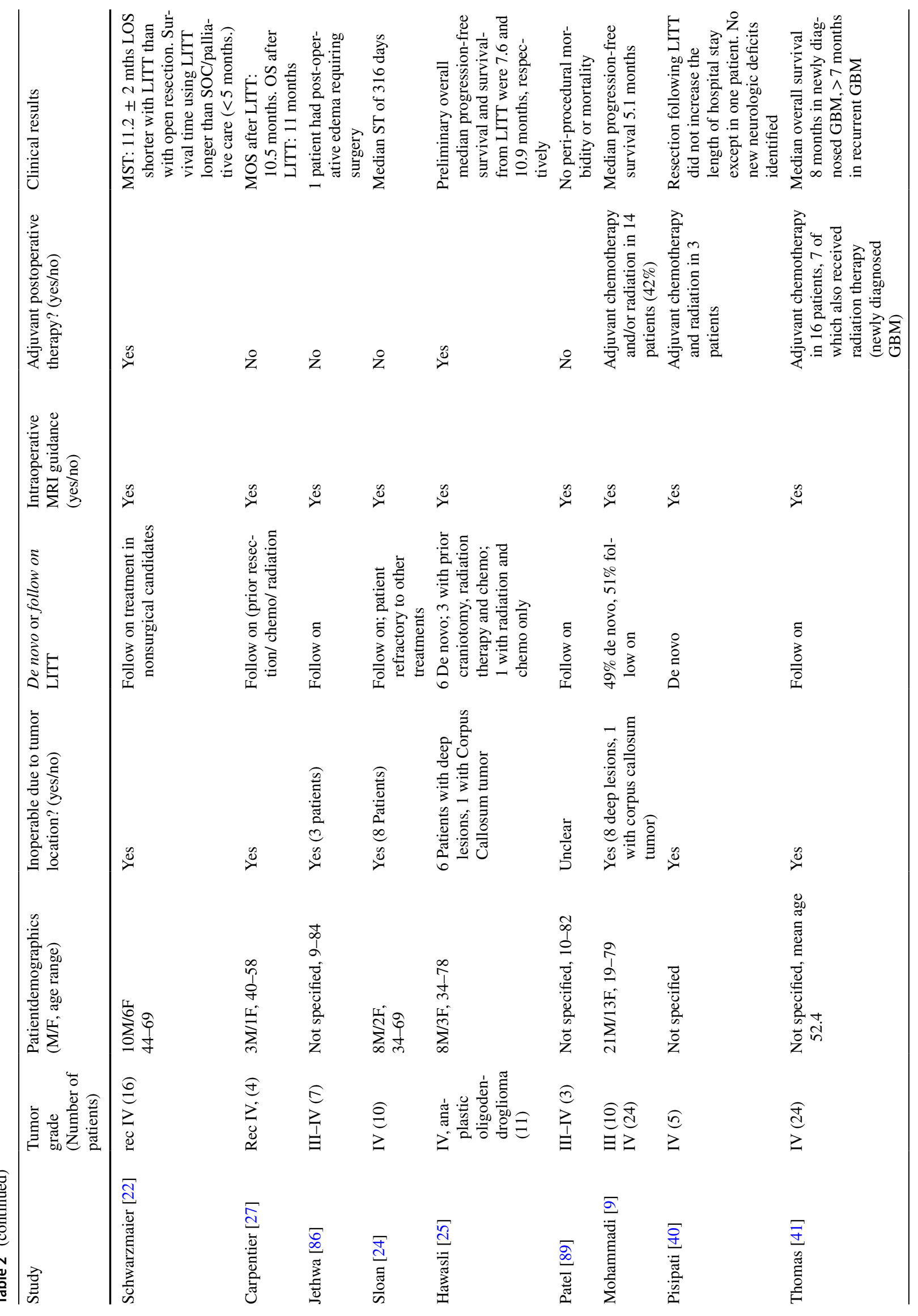




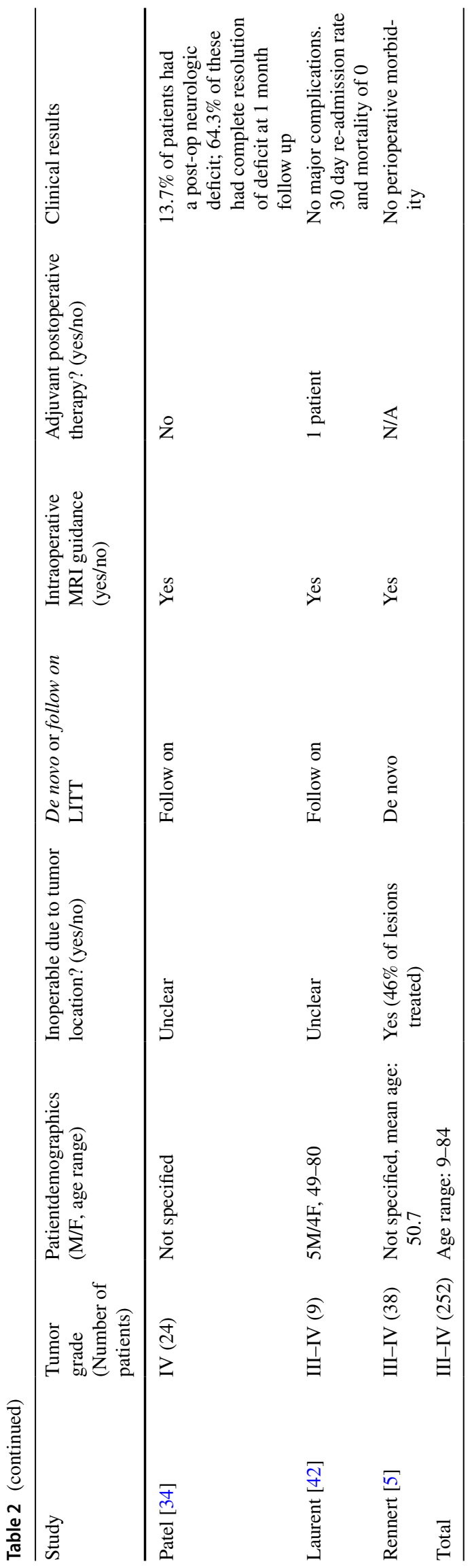

\section{Conclusions}

LITT has been in development for the past two decades and has now demonstrated efficacy in the treatment of glioma of various grades and types. While most of the publications have been retrospective case studies, these demonstrate that LITT is a potentially beneficial focal form of therapy in patients with gliomas who are not otherwise candidates for open surgery or have exhausted other therapeutic modalities. This noninvasive, anatomically and physiologically personalized form of treatment has the added asset of incurring substantially less hospitals costs and posing much less periprocedural medical risks to the patient.

\section{Treatment of brain metastasis}

An estimated $25-35 \%$ of all cancer patients suffer from brain metastasis (BM), though the true incidence of BM remains unknown and is expected to rise in parallel with the increasing incidence of cancer and with the aging of society [54]. Additionally, since most effective cytotoxic drugs and monoclonal antibodies drugs penetrate the blood brain barrier (BBB) only poorly, patients are living longer from diagnosis until tumors develop in the CNS and possibly other sequestered locations.

The lack of efficacy of chemotherapy for BM treatment has resulted in a dependence on surgical resection and/or ionizing radiation. Radiation can be delivered as whole brain radiation therapy (WBRT), which is dosed to the entire brain typically over 10-15 sessions; or as stereotactic radiosurgery (SRS), where multiple high energy beams converge specifically on the target with rapid dose falloff in 1-5 fractions. Because WBRT is associated with increased risk of neurocognitive deficits, the majority of patients afflicted with a limited number of BM are treated with SRS [14, 55-57]. The current clinical practice suggest that SRS remains the first line treatment for BM patients in this context.

In recent years, however, LITT, has emerged as a therapeutic option for BM that recur after SRS [3,5]. These BM will be referred to as BMRS (brain metastasis recurred after SRS). In this section, the efficacy of LITT in this context will be reviewed. Focus will lie only on studies where histologically confirmed BM recurrence were treated with LITT. Studies primarily focusing on radiation necrosis $(\mathrm{RN})$ will be reviewed in a separate section.

\section{Local control}

Carpentier et al. were the first to report local control for LITT treated BMRS [58]. In this study, local control was defined as post-treatment contrast-enhancing volume 
(CEv) smaller than pre-treatment CEv. Using this definition, the authors report that local control was $60 \%$ for partially ablated lesions $(n=6)$ and $85 \%$ for completely ablated lesions $(n=9)$. Ahluwalia et al. reported a multicenter study involving 42 patients (20 with BMRS) treated with LITT [57]. Of the BMRS patients, local control was observed in $100 \%$ of completely ablated BMRS, but only $37.5 \%$ of incompletely treated lesions suffered disease progression. Similarly, Ali et al. found that $100 \%$ local control was achieved with completely ablated BMRS, but only $65.3 \%$ if $<80 \%$ of BMRS was ablated [14]. In a subset of these patients treated with adjuvant radiosurgery, local control was $100 \%$ irrespective of the extent of ablation. Rao et al. similarly reported local control in $85.7 \%$ of patients undergoing complete ablation a series of 14 BMRS patients [59].

\section{Overall survival}

Median overall survival in LITT-treated BMRS patients ranges from 5.8 months to 19.8 months, with one year survival of $0-65 \%[25,58-60]$. The longest reported survivorship after LITT was 30 months. Most patients died within months of laser ablation, suggesting that systemic disease control remains a key determinant of survival for patients with BMRS as with SRS [1, 25, 58-60].

\section{Neurologic and functional status}

Chaunzwa et al. report stable or improved KPS was observed in $13 / 22$ patients $(59 \%)$ who had pre-operative KPS of 70-100. Ablation of $>90 \%$ of BMRS was associated with a higher likelihood of improved KPS. This study did not stratify results by BMRS or RN and should be interpreted in this context [61]. Similarly, in a series of 42 BMRS patients, Ahluwalia et al. noted $87 \%$ of patients experienced stable or improved KPS at last follow-up [57]. Reduction in steroid requirement was reported in $31 \%$ of these cases.

\section{Complications}

The complication rate associated with LITT of BMRS was $<10 \%$. Complications include catheter misplacement, infection, hydrocephalus, hemorrhage, thermal injury to normal brain, and malignant edema requiring re-operation for hemicraniectomy. In the four cases of post-LITT malignant cerebral edema requiring hemicraniectomy, ablated volume ranged from 29 to $70 \mathrm{~cm}^{3}$ [14, 62-64]. This suggests that LITT of larger lesions should be avoided, or combined with debulking as previously noted [1].

\section{Conclusion}

The available retrospective studies suggest that LITT is a good option for patients suffering from BMRS. Neurological outcome is generally favorable and complete ablation increase the likelihood of local control. Prospective studies will be needed to better understand optimal application of LITT for BMRS.

\section{LITT for cerebral radiation necrosis}

Radiation necrosis ( $\mathrm{RN}$ ), a severe local tissue reaction which most commonly occurs 3-12 months after completion of radiation therapy, is a common complication of radiation therapy (RT) for primary and metastatic brain tumors, occurring $4.7-9.2 \%$ in patients with metastatic brain tumors undergoing SRS with higher doses associated with a higher risk of RN [65-68]. Although most cases of RN are self-limiting, symptomatic lesions may require treatment. Steroids are the mainstay of treatment for RN by inhibiting the pro-inflammatory cytokine response from radiation [69]. However, the treatment response is transient and some patient may become steroid dependent. In addition, steroid treatment carries significant side effects, including infection, gastrointestinal bleeding, myopathy and diabetes. Bevacizumab, a vascular endothelial growth factor inhibitor, has also been shown to be effective in RN [70]. Other treatment such as Vitamin E, hyperbaric oxygen, pentoxifylline and anticoagulation have also been used with limited efficacy [71-73]. For a minority of patients, surgery may be necessary to relieve mass effect. Open surgery provides the benefit of immediate relief of mass effect and tissue diagnosis, but carries attendant risks of surgical morbidity, including stroke, hemorrhage, and wound-related complications and usually requires a pause in systemic treatments to allow for wound healing.

LITT has emerged as an increasingly popular treatment for recurrent or enlarging enhancing lesions after RT and or SRS for brain tumors. When performed with a stereotactic biopsy, as it is typically performed, LITT provides the advantage of combining the diagnostic procedure (to assess tumor recurrence versus $\mathrm{RN}$ ) along with cytoreductive treatment with a minimally invasive technique approach and short hospitals stay. As such, it may minimize the amount of time needed to be off systemic treatments and lessen recovery time. On the downside, it is not suitable for patients already suffering from mass effect and is subject to sampling error as with all stereotactic biopsies. No RCTs have been performed to date examining the role of LITT in RN, but multiple retrospective studies have demonstrated LITT to be a promising treatment modality.

The use of LITT for RN was first described in 2012 [74]. Since then, multiple retrospective studies have been 
published examining the role of LITT in $\mathrm{RN}[11,57,59,60$, 75-81]. Most studies have contained a mixture of patients with either recurrent tumor or RN post-SRS for brain metastasis or glioma, with three focused solely on RN [11,57, 59, 60, 75-81].

\section{Control of RN and complications}

In the studies where the ablation percentage was calculated, between 86.4 and $100 \%$ of the contrast enhancing volume was ablated [57, 61, 75, 77, 80, 82]. Early studies were encouraging, with most patients achieving palliation of symptoms, especially in those patients who were able to attain complete ablations $[11,79]$. Hong et al. performed a retrospective cohort study comparing LITT to craniotomy for patients with progressive enhancement post-SRS for metastatic disease. For the patients undergoing LITT with biopsy proven RN, they demonstrated a local control rate of $87.4 \%$ at 18 months. Of note, in patients who were found to have tumor, local control rate was $61.5 \%$ compared to $87.4 \%$ for those with RN [75]. Similarly, Ahluwalia et al. showed a $91 \%$ local control rate at 12 weeks for the 19 patients with RN who underwent LITT, compared to $54 \%$ for the 20 with recurrent tumor [57]. Smith et al. published a case series with a mixture of histologies including low and high grade gliomas, meningioma and metastatic disease. For the seven patients with metastatic disease, the local control rate was $86 \%$. Several other studies were done without biopsies, thus response rates represent a mixture of recurrent metastatic disease and RN $[11,59,76]$. Hernandez et al. reported a series of 59 patients with 74 treated lesions, which was a continuation of an earlier work by Rao et al. [76]. In that study, only ten of the 59 (16.9\%) patients had local recurrence of disease after LITT.

Complication rates ranged from $0 \%-30 \%[11,57,59,60$, 75-81]. Most of the complications were due to hemorrhage, seizures, new or worsened motor deficit due to proximity of the corticospinal tract, as well as systemic complications such as myocardial infarction, deep vein thrombosis and pulmonary embolism. This is in line with other LITT case series. Of note, in the retrospective cohort study performed by Hong et al., they found a similar rate of complications in patients undergoing LITT vs. craniotomy [75].

\section{Weaning of steroids}

$\mathrm{RN}$ can lead to steroid dependence which is sometimes as debilitating as recurrent tumor, thus, most of the studies examined the ability to wean off steroids after LITT [11, $57,59,61,75,78-80,82]$. Due to variability in reporting, it is difficult to draw generalized conclusions. However, typically steroids could be weaned within 2-4 weeks in many cases $(70-100 \%)[59,61,77,78]$. In two of the larger series by Ahluwalia et al. and Hong et al., $31 \%$ were weaned off at 12 weeks and $34.8 \%$ patients were weaned off at 4 weeks, respectively $[57,75]$. Finally, in a multicenter retrospective case series by Chaunzwa et al., 19/30 (63.3\%) patients had adequate steroid use data for analysis. Eleven patients had symptom relief with steroids pre-LITT (36.7\%), of which 9 (30\%) were able to wean off steroids completely by a median of 5 weeks [61].

\section{Conclusions}

LITT appears to be a viable treatment for $\mathrm{RN}$ in several retrospective studies, though no prospective studies or trials have been reported. Complication rates for LITT in the setting of RN are similar to LITT performed for other oncological conditions and appear to be lower than the rate seen in craniotomies. Most patients with biopsy proven RN will be able to wean off steroids. Finally, biopsy does appear to confer valuable data, as it may influence treatment post-LITT.

\section{LITT for other neoplastic conditions}

The bulk of the reported data about LITT for oncology indications has focused on gliomas, recurrent metastases and RN. However, though there have been no prospective studies of other types of intracranial lesions, there have been a few case series reviewing the use of LITT for dural-based lesions, largely meningiomas [82-84]. Ivan et al. described a group of five patients with recurrent extra-axial masses including three grade I meningiomas, one grade III meningioma, and one solitary fibrous tumor. All had clear evidence of tumor progression after initial treatment including craniotomy and radiation, but were poor candidates for open surgery. In this case series, the grade I meningiomas showed good response to LITT, with $52 \%$ reduction of the size of the lesions at 3 months. The other two patients showed early progression at three months for the anaplastic meningioma and ten months for the solitary fibrous tumor, in line with the aggressive pathology of the masses [84]. A follow up study of the same group of patients demonstrated no evidence of recurrence of the grade I meningiomas with a follow up of seven to ten months [84]. Similarly, in another small retrospective case series, two patients with anaplastic meningiomas and one with benign meningioma were treated with LITT. Average ablation coverage was $75 \%$, with both of the anaplastic meningioma patients having early progression [82]. The grade 1 meningioma was recurrence-free at 28 weeks. Unfortunately, this patient had severe edema after the procedure leading to near hemiplegia. Although the hemiplegia eventually resolved, it took six months to do so [82]. Although these studies describe only a very small number of patients, available data demonstrate that the localized 
pathology of the meningiomas defines the localized clinical course of this disease, which tends to recur locally rather than at distant sites regardless of what treatment modality is utilized.

LITT has also been employed for other more commonly seen pediatric intra-axial pathologies, such as ependymomas, primitive neuroectodermal tumors, subependymal giant cell astrocytoma, pilocytic astrocytoma, medulloblastoma, choroid plexus xanthogranuloma, and ganglioglioma [62, 85-88]. All are relatively small case series, but treatment results and complications are in line with the results seen in adult patients [62, 85-89]. Notably in the case series by Tovar-Spinoza and Choi, many of the lesions treated were difficult or potentially dangerous areas to treat such as the cerebellar peduncle, thalamus or midbrain. Despite this, only two out of eleven patients (18.2\%) had complications consisting of transient weakness in both patients, and akinetic mutism and eye motion disorder in one of the patients, of which both patients largely recovered. In addition, durable response to treatment was seen, with decrease in tumor volume out to six months [85]. In summary, LITT for pediatric pathologies is analogous to adult tumors with the caveat that the pediatric patients may have greater capacity for neurological recovery.

\section{Treatment for spine tumors}

Advances in cancer therapy has led to longer survival time of patients with various cancer subtypes. Multidisciplinary teams of spine surgeon, radiation and medical oncologists, pain and rehabilitation specialists, and interventional radiologist have formed in order to deliver the best spine cancer treatment. The goals of treatment for metastatic spine disease remain palliative and aside from traditional goals such as local tumor control, achievement of symptom palliation and improved health-related quality of life (HRQoL) is paramount [90].

\section{Spinal LITT}

Patients with metastatic spinal tumors that cause epidural compression benefit from a combination of surgical decompression known as separation surgery followed by radiation therapy; in fact, Laufer et al. have demonstrated that separation surgery in combination with stereotactic radiation provides one-year local control rates of more than $91 \%$ regardless of tumor histology radiosensitivity [91]. Spinal LITT represents a novel minimally invasive approach to treating metastatic spine tumors. The surgical aim of LITT to treat spinal metastasis is to achieve local tumor control, allow for fast recovery, minimize postoperative pain and morbidity, and curtail delays in initiating or interrupting systemic therapies directed at the primary tumor [92]. The LITT technique has been introduced as an alternative to separation surgery and is used in a synergistic fashion with radiation therapy. The surgical aim of LITT to treat spinal metastasis is to achieve local tumor control, allow for fast recovery, minimize postoperative pain and morbidity, and curtail delays in initiating or interrupting systemic therapies directed at the primary tumor [92]. Spinal LITT is currently being done only at a small number of centers and most of the reports are retrospective.

Ahrar and Stafford first reported the use of LITT to treat spinal metastasis in 2010, but their study excluded tumors extending to the epidural space [93]. The authors concluded that LITT was a safe and reliable technique. More recently, Tatsui et al. found that LITT is safe and effective in patients with mild epidural compression secondary to tumor extension utilizing LITT as an option to replace separation surgery for specific patients as well as an adjunct to SSRS [94]. Specifically, patients go through LITT and then SSRS in standard doses to cover the gross tumor volume, as if no thermal ablation were performed. If spinal instability is suspected, percutaneous placement of spinal instrumentation and cement augmentation can be done in the same sitting, though this is not part of the LITT per se.

Details of operative considerations, placement of probe and ablation steps have been previously published in detail. Briefly, LITT procedures are done with an intraoperative MRI (iMRI) [90]. The diameter of the MRI bore must be large enough to fit the patient in the prone position with part of the probe protruding about $6 \mathrm{~cm}$ above the skin. The patient is positioned prone over gel rolls placed in parallel along the patient body axis with the arms tucked to the side. The probe is placed a distance of $6 \mathrm{~mm}$ from the ventral dural border of the posterior vertebral body using CT-based image guidance [95]. Tatsui et al. have found that a distance of $5 \mathrm{~mm}$ on each side of the laser fiber is covered by temperatures associated with tumor cell death [96]. If more coverage is needed, more than one probe may be used in various positions from different entry points in order to increase the area of cell death [95]. LITT is then performed. The heating process is monitored in real time with thermal MRI, and once the temperature reaches a critical level at the dural edge, the system deactivates, protecting the spinal cord from thermal damage. The LITT procedure is followed by SSRS in standard doses to cover the gross tumor volume. Patients undergoing LITT are admitted on the same day of the procedure with the average length of the procedure approaching eight hours. This time includes patient anesthesia and positioning, obtaining the fluoroscopic match for navigation, placing the access cannulas into the desired location in the epidural tumor, transferring the patient into the MRI magnet, obtaining the localization for each fiber, obtaining parameters for the thermal map for each fiber, performing an average of five cycles of heating per puncture 
with ventilator pauses, evaluating somatosensory evoked potential monitoring between each cycle, obtaining a final scan with and without contrast to evaluate the ablated tissue, closing the stab wounds, and transferring the patient to a stretcher for extubation. Post operatively, individuals are admitted to regular hospital beds after the procedure, and the median hospital stay was two days. Patients are discharged once pain is under control and they are typically capable of ambulating without assistance.

\section{Overall Conclusions}

LITT is emerging as a safe, reliable, minimally invasive clinical approach, particularly for deep seated, focal malignant brain tumors and radiation necrosis. The role of LITT for treatment of other types of tumors of the brain and for spine tumors appears to be evolving at a small number of centers. While the technology appears to be safe and increasingly utilized, there have been few prospective clinical trials, and most published studies combine different pathologies in the same report. Well designed prospective trials for each of the various pathologies currently treated will be required to firmly establish the role of LITT in the treatment of lesions of the brain and spine.

Open Access This article is licensed under a Creative Commons Attribution 4.0 International License, which permits use, sharing, adaptation, distribution and reproduction in any medium or format, as long as you give appropriate credit to the original author(s) and the source, provide a link to the Creative Commons licence, and indicate if changes were made. The images or other third party material in this article are included in the article's Creative Commons licence, unless indicated otherwise in a credit line to the material. If material is not included in the article's Creative Commons licence and your intended use is not permitted by statutory regulation or exceeds the permitted use, you will need to obtain permission directly from the copyright holder. To view a copy of this licence, visit http://creativecommons.org/licenses/by/4.0/.

\section{References}

1. Wright J, Chugh J, Wright $\mathrm{CH}$, Alonso F, Hdeib A, Gittleman H, Barnholtz-Sloan J, Sloan AE (2016) Laser interstitial thermal therapy followed by minimal-access transsulcal resection for the treatment of large and difficult to access brain tumors. Neurosurg Focus 41:E14. https://doi.org/10.3171/2016.8.FOCUS16233

2. Sharma M, Krivosheya D, Borghei-Razavi H, Barnett GH, Mohammadi AM (2018) Laser interstitial thermal therapy for an eloquent region supratentorial brain lesion. Neurosurg Focus 44:V4. https://doi.org/10.3171/2018.4.FocusVid.17737

3. Sharma M, Balasubramanian S, Silva D, Barnett GH, Mohammadi AM (2016) Laser interstitial thermal therapy in the management of brain metastasis and radiation necrosis after radiosurgery: an overview. Expert Rev Neurother 16:223-232. https://doi. org/10.1586/14737175.2016.1135736

4. Schwarzmaier HJ, Eickmeyer F, von Tempelhoff W, Fiedler VU, Niehoff H, Ulrich SD, Ulrich F (2005) MR-guided laser irradiation of recurrent glioblastomas. J Magn Reson Imaging 22:799-803. https://doi.org/10.1002/jmri.20446

5. Rennert RC, Khan U, Tatter SB, Field M, Toyota B, Fecci PE, Judy K, Mohammadi AM, Landazuri P, Sloan A, Leuthardt E, Chen CC (2018) Patterns of clinical use of stereotactic laser ablation: analysis of a multicenter prospective registry. World Neurosurg 116:e566-e570. https://doi.org/10.1016/j.wneu.2018.05.039

6. Rahmathulla G, Recinos PF, Kamian K, Mohammadi AM, Ahluwalia MS, Barnett GH (2014) MRI-guided laser interstitial thermal therapy in neuro-oncology: a review of its current clinical applications. Oncology 87:67-82. https://doi.org/10.1159/00036 2817

7. Norred SE, Johnson JA (2014) Magnetic resonance-guided laser induced thermal therapy for glioblastoma multiforme: a review. Biomed Res Int 2014:761312. https://doi. org/10.1155/2014/761312

8. Mohammadi AM, Schroeder JL (2014) Laser interstitial thermal therapy in treatment of brain tumors-the neuroBlate system. Expert Rev Med Devices 11:109-119. https://doi. org/10.1586/17434440.2014.882225

9. Mohammadi AM, Hawasli AH, Rodriguez A, Schroeder JL, Laxton AW, Elson P, Tatter SB, Barnett GH, Leuthardt EC (2014) The role of laser interstitial thermal therapy in enhancing progression-free survival of difficult-to-access high-grade gliomas: a multicenter study. Cancer Med 3:971-979. https:// doi.org/10.1002/cam4.266

10. Ivan ME, Mohammadi AM, De Deugd N, Reyes J, Rodriguez G, Shah A, Barnett GH, Komotar RJ (2016) Laser ablation of newly diagnosed malignant gliomas: a meta-analysis. Neurosurgery 79(Suppl 1):S17-S23. https://doi.org/10.1227/NEU.00000 00000001446

11. Carpentier A, McNichols RJ, Stafford RJ, Itzcovitz J, Guichard JP, Reizine D, Delaloge S, Vicaut E, Payen D, Gowda A, George B (2008) Real-time magnetic resonance-guided laser thermal therapy for focal metastatic brain tumors. Neurosurgery. https ://doi.org/10.1227/01.neu.0000335007.07381.df

12. Beaumont TL, Mohammadi AM, Kim AH, Barnett GH, Leuthardt EC (2018) Magnetic resonance imaging-guided laser interstitial thermal therapy for glioblastoma of the corpus callosum. Neurosurgery 83:556-565. https://doi.org/10.1093/neuro s/nyx518

13. Barnett GH, Chen CC, Gross RE, Sloan AE (2016) Introduction: laser ablation techniques. Neurosurg Focus 41:E1. https://doi. org/10.3171/2016.8.FOCUS16319

14. Ali MA, Carroll KT, Rennert RC, Hamelin T, Chang L, Lemkuil BP, Sharma M, Barnholtz-Sloan JS, Myers C, Barnett GH, Smith K, Mohammadi AM, Sloan AE, Chen CC (2016) Stereotactic laser ablation as treatment for brain metastases that recur after stereotactic radiosurgery: a multiinstitutional experience. Neurosurg Focus 41:E11. https://doi.org/10.3171/2016.7.FOCUS16227

15. Anzai Y, Lufkin R, DeSalles A, Hamilton DR, Farahani K, Black KL (1995) Preliminary experience with MR-guided thermal ablation of brain tumors. AJNR Am J Neuroradiol 16:39-48

16. Mohammadi AM, Sharma M, Beaumont TL, Juarez KO, Kemeny H, Dechant C, Seas A, Sarmey N, Lee BS, Jia X, Fecci PE, Baehring J, Moliterno J, Chiang VL, Ahluwalia MS, Kim AH, Barnett GH, Leuthardt EC (2018) Upfront Magnetic resonance imagingguided stereotactic laser-ablation in newly diagnosed glioblastoma: a multicenter review of survival outcomes compared to a matched cohort of biopsy-only patients. Neurosurgery. https://doi. org/10.1093/neuros/nyy449

17. Wright JM, Staudt MD, Alonso A, Miller JP, Sloan AE (2018) A novel use of the neuroblate sideFire probe for minimally invasive disconnection of a hypothalamic hamartoma in a child with gelastic seizures. J Neurosurg Pediatr 21:302-307. https://doi. org/10.3171/2017.9.PEDS1747 
18. Maroon JC, Onik G, Quigley MR, Bailes JE, Wilberger JE, Kennerdell JS (1992) Cryosurgery re-visited for the removal and destruction of brain, spinal and orbital tumours. Neurol Res 14:294-302

19. Ram Z, Cohen ZR, Harnof S, Tal S, Faibel M, Nass D, Maier SE, Hadani M, Mardor Y (2006) Magnetic resonance imaging-guided, high-intensity focused ultrasound for brain tumor therapy. Neurosurgery 59:949-955. https://doi.org/10.1227/01.NEU.0000254439 .02736.D8

20. Bown SG (1983) Phototherapy in tumors. World J Surg 7:700709. https://doi.org/10.1007/bf01655209

21. Leonardi MA, Lumenta CB (2002) Stereotactic guided laserinduced interstitial thermotherapy (SLITT) in gliomas with intraoperative morphologic monitoring in an open MR: clinical expierence. Minim Invasive Neurosurg 45:201-207. https://doi. org/10.1055/s-2002-36203

22. Schwarzmaier HJ, Eickmeyer F, von Tempelhoff W, Fiedler VU, Niehoff H, Ulrich SD, Yang Q, Ulrich F (2006) MR-guided laserinduced interstitial thermotherapy of recurrent glioblastoma multiforme: preliminary results in 16 patients. Eur J Radiol 59:208215. https://doi.org/10.1016/j.ejrad.2006.05.010

23. Schwarzmaier HJ, Yaroslavsky IV, Yaroslavsky AN, Fiedler V, Ulrich F, Kahn T (1998) Treatment planning for MRI-guided laser-induced interstitial thermotherapy of brain tumors-the role of blood perfusion. J Magn Reson Imaging 8:121-127

24. Sloan AE, Ahluwalia MS, Valerio-Pascua J, Manjila S, Torchia MG, Jones SE, Sunshine JL, Phillips M, Griswold MA, Clampitt M, Brewer C, Jochum J, McGraw MV, Diorio D, Ditz G, Barnett GH (2013) Results of the neuroblate system first-in-humans phase I clinical trial for recurrent glioblastoma: clinical article. J Neurosurg 118:1202-1219. https://doi.org/10.3171/2013.1.jns1291

25. Hawasli AH, Bagade S, Shimony JS, Miller-Thomas M, Leuthardt EC (2013) Magnetic resonance imaging-guided focused laser interstitial thermal therapy for intracranial lesions: single-institution series. Neurosurgery 73:1007-1017. https://doi.org/10.1227/ neu.0000000000000144

26. Karampelas I, Sloan AE (2018) Laser-induced interstitial thermotherapy of gliomas. Prog Neurol Surg 32:14-26. https://doi. org/10.1159/000469676

27. Carpentier A, Chauvet D, Reina V, Beccaria K, Leclerq D, McNichols RJ, Gowda A, Cornu P, Delattre JY (2012) MR-guided laser-induced thermal therapy (LITT) for recurrent glioblastomas. Lasers Surg Med 44:361-368. https://doi.org/10.1002/lsm.22025

28. Ascher PW, Justich E, Schröttner O (1991) A new surgical but less invasive treatment of central brain tumours Preliminary report. Acta Neurochir Suppl (Wien) 52:78-80. https://doi. org/10.1007/978-3-7091-9160-6_22

29. Roux FX, Merienne L, Fallet-Bianco C, Beuvon F, Devaux B, Leriche B, Cioloca C (1992) Stereotaxic laser interstitial thermotherapy. A new alternative in the therapeutic management of some brain tumors. Neurochirurgie 38:238-244

30. Kahn T, Bettag M, Ulrich F, Schwarzmaier HJ, Schober R, Furst G, Modder U (1994) MRI-guided laser-induced interstitial thermotherapy of cerebral neoplasms. J Comput Assist Tomogr 18:519-532. https://doi.org/10.1097/00004728-199407000-00002

31. Kahn T, Harth T, Bettag M, Schwabe B, Ulrich F, Schwarzmaier HJ, Modder U (1997) Preliminary experience with the application of gadolinium-DTPA before MR imaging-guided laser-induced interstitial thermotherapy of brain tumors. J Magn Reson Imaging 7:226-229

32. Schwabe B, Kahn T, Harth T, Ulrich F, Schwarzmaier HJ (1997) Laser-induced thermal lesions in the human brain: short- and long-term appearance on MRI. J Comput Assist Tomogr 21:818825. https://doi.org/10.1097/00004728-199709000-00031

33. von Tempelhoff W, Toktamis S, Schwarzmeier H-J, Eickmeyer F, Niehoff H, Ulrich F (2002) LITT (Laser induced interstitial thermotherapy) of benign and malignant gliomas in the OPEN MR (0.5 Tesla, GE Signa SP). Med Laser Appl 17:170-178. https ://doi.org/10.1078/1615-1615-00060

34. Patel P, Patel NV, Danish SF (2016) Intracranial MR-guided laserinduced thermal therapy: single-center experience with the visualase thermal therapy system. J Neurosurg 125:853-860. https:// doi.org/10.3171/2015.7.JNS15244

35. Miller BA, Salehi A, Limbrick DD, Smyth MD (2017) Applications of a robotic stereotactic arm for pediatric epilepsy and neurooncology surgery. J Neurosurg Pediatr 20:364-370. https:// doi.org/10.3171/2017.5.PEDS1782

36. Karsy M, Patel DM, Bollo RJ (2018) Trapped ventricle after laser ablation of a subependymal giant cell astrocytoma complicated by intraventricular gadolinium extravasation: case report. J Neurosurg Pediatr 21:523-527. https://doi.org/10.3171/2017.11. PEDS17518

37. Buckley RT, Wang AC, Miller JW, Novotny EJ, Ojemann JG (2016) Stereotactic laser ablation for hypothalamic and deep intraventricular lesions. Neurosurg Focus 41:E10. https://doi. org/10.3171/2016.7.focus 16236

38. Dadey DY, Kamath AA, Smyth MD, Chicoine MR, Leuthardt EC, Kim AH (2016) Utilizing personalized stereotactic frames for laser interstitial thermal ablation of posterior fossa and mesiotemporal brain lesions: a single-institution series. Neurosurg Focus 41:E4. https://doi.org/10.3171/2016.7.focus 16207

39. Fan M, Ascher PW, Schrottner O, Ebner F, Germann RH, Kleinert R (1992) Interstitial $1.06 \mathrm{Nd}$ :YAG laser thermotherapy for brain tumors under real-time monitoring of MRI: experimental study and phase I clinical trial. J Clin Laser Med Surg 10:355361. https://doi.org/10.1089/clm.1992.10.355

40. Pisipati S, Smith KA, Shah K, Ebersole K, Chamoun RB, Camarata PJ (2016) Intracerebral laser interstitial thermal therapy followed by tumor resection to minimize cerebral edema. Neurosurg Focus 41:E13. https://doi.org/10.3171/2016.7.focus16224

41. Thomas JG, Rao G, Kew Y, Prabhu SS (2016) Laser interstitial thermal therapy for newly diagnosed and recurrent glioblastoma. Neurosurg Focus 41:E12. https://doi. org/10.3171/2016.7.FOCUS16234

42. Laurent D, Oliveria SF, Shang M, Bova F, Freedman R, Rahman M (2018) Techniques to ensure accurate targeting for delivery of awake laser interstitial thermotherapy. Oper Neurosurg (Hagerstown) 15:454-460. https://doi.org/10.1093/ons/opx290

43. Sakai T, Fujishima I, Sugiyama K, Ryu H, Uemura K (1992) Interstitial laserthermia in neurosurgery. J Clin Laser Med Surg 10:37-40. https://doi.org/10.1089/clm.1992.10.37

44. Reimer P, Bremer C, Horch C, Morgenroth C, Allkemper T, Schuierer G (1998) MR-monitored LITT as a palliative concept in patients with high grade gliomas: preliminary clinical experience. J Magn Reson Imaging 8:240-244

45. Sneed PK, Stauffer PR, McDermott MW, Diederich CJ, Lamborn KR, Prados MD, Chang S, Weaver KA, Spry L, Malec MK, Lamb SA, Voss B, Davis RL, Wara WM, Larson DA, Phillips TL, Gutin PH (1998) Survival benefit of hyperthermia in a prospective randomized trial of brachytherapy boost +/- hyperthermia for glioblastoma multiforme. Int J Radiat Oncol Biol Phys 40:287-295. https://doi.org/10.1016/s0360 $-3016(97) 00731-1$

46. Stepp HG, Beck T, Beyer W, Pongratz T, Sroka R, Baumgartner R, Reulen HJ (2005) Fluorescence-guided resections and photodynamic therapy for malignant gliomas using 5-aminolevulinic acid. Proc SPIE 5686:547-557

47. Sloan AE (2012) Glioblastoma in the elderly. J Neurosurg 116:355-356. https://doi.org/10.3171/2011.6.JNS11982

48. Cushing K, Kushnir V (2016) Gastrointestinal bleeding following LVAD placement from top to bottom. Dig Dis Sci 61:1440-1447. https://doi.org/10.1007/s10620-016-4123-4 
49. Hawasli AH, Kim AH, Dunn GP, Tran DD, Leuthardt EC (2014) Stereotactic laser ablation of high-grade gliomas. Neurosurg Focus 37:E1. https://doi.org/10.3171/2014.9.focus 14471

50. Leuthardt EC, Duan C, Kim MJ, Campian JL, Kim AH, MillerThomas MM, Shimony JS, Tran DD (2016) Hyperthermic laser ablation of recurrent glioblastoma leads to temporary disruption of the peritumoral blood brain barrier. PLoS ONE 11:e0148613. https://doi.org/10.1371/journal.pone.0148613

51. Laser Interstitial Thermal Therapy and Lomustine in Treating Patients With Recurrent Glioblastoma or Anaplastic Astrocytoma. https://ClinicalTrials.gov/show/NCT03022578.

52. Laser Interstitial Thermotherapy (LITT) Combined With Checkpoint Inhibitor for Recurrent GBM (RGBM). https://ClinicalTr ials.gov/show/NCT03277638.

53. Avelumab With Laser Interstitial Therapy for Recurrent Glioblastoma. https://ClinicalTrials.gov/show/NCT03341806.

54. Brown DA, Himes BT, Major BT, Mundell BF, Kumar R, Kall B, Meyer FB, Link MJ, Pollock BE, Atkinson JD, Van Gompel JJ, Marsh WR, Lanzino G, Bydon M, Parney IF (2018) Cranial tumor surgical outcomes at a high-volume academic referral center. Mayo Clin Proc 93:16-24. https://doi.org/10.1016/j.mayoc p.2017.08.023

55. Christ SM, Mahadevan A, Floyd SR, Lam FC, Chen CC, Wong ET, Kasper EM (2015) Stereotactic radiosurgery for brain metastases from malignant melanoma. Surg Neurol Int 6:S355-365. https://doi.org/10.4103/2152-7806.163315

56. Alva Venur V, Kotecha R, Chen Z, Chao ST, Elson P, Suh JH, Ahluwalia MS (2015) Impact of BRAF mutation in patients with brain metastasis from melanoma. J Clin Oncol 33:e13016e13016. https://doi.org/10.1200/jco.2015.33.15_suppl.e13016

57. Ahluwalia M, Barnett GH, Deng D, Tatter SB, Laxton AW, Mohammadi AM, Leuthardt E, Chamoun R, Judy K, Asher A, Essig M, Dietrich J, Chiang VL (2018) Laser ablation after stereotactic radiosurgery: a multicenter prospective study in patients with metastatic brain tumors and radiation necrosis. J Neurosurg 130:804-811. https://doi.org/10.3171/2017.11.jns171273

58. Carpentier A, McNichols RJ, Stafford RJ, Guichard JP, Reizine D, Delaloge S, Vicaut E, Payen D, Gowda A, George B (2011) Laser thermal therapy: real-time MRI-guided and computer-controlled procedures for metastatic brain tumors. Lasers Surg Med 43:943-950. https://doi.org/10.1002/lsm.21138

59. Rao MS, Hargreaves EL, Khan AJ, Haffty BG, Danish SF (2014) Magnetic resonance-guided laser ablation improves local control for postradiosurgery recurrence and/or radiation necrosis. Neurosurgery 74:658-667. https://doi.org/10.1227/neu.0000000000 000332

60. Chaunzwa TL, Deng D, Leuthardt EC, Tatter SB, Mohammadi AM, Barnett GH, Chiang VL (2018) Laser thermal ablation for metastases failing radiosurgery: a multicentered retrospective study. Neurosurgery 82:56-63. https://doi.org/10.1093/neuros/ nyx 142

61. Chaunzwa TL, Deng D, Leuthardt EC, Tatter SB, Mohammadi AM, Barnett GH, Chiang VL (2017) Laser thermal ablation for metastases failing radiosurgery: a multicentered retrospective study. Neurosurgery 82:56-63. https://doi.org/10.1093/neuros/ nyx 142

62. Patel NV, Jethwa PR, Shetty A, Danish SF (2015) Does the realtime thermal damage estimate allow for estimation of tumor control after MRI-guided laser-induced thermal therapy? Initial experience with recurrent intracranial ependymomas. J Neurosurg Pediatr 15:363-371. https://doi.org/10.3171/2014.10.peds13698

63. Jethwa PR, Lee JH, Assina R, Keller IA, Danish SF (2011) Treatment of a supratentorial primitive neuroectodermal tumor using magnetic resonance-guided laser-induced thermal therapy. J Neurosurg Pediatr 8:468-475. https://doi.org/10.3171/2011.8.peds1 1148
64. Purvee P, Nitesh VP, Shabbar FD (2016) Intracranial MR-guided laser-induced thermal therapy: single-center experience with the visualase thermal therapy system. J Neurosurg JNS 125:853-860. https://doi.org/10.3171/2015.7.JNS15244

65. Kim JW, Park HR, Lee JM, Kim JW, Chung H-T, Kim DG, Jung H-W, Paek SH (2016) Fractionated stereotactic gamma knife radiosurgery for large brain metastases: a retrospective single center study. PLoS ONE 11:e0163304. https://doi.org/10.1371/ journal.pone.0163304

66. Gerosa M, Nicolato A, Foroni R, Zanotti B, Tomazzoli L, Miscusi M, Alessandrini F, Bricolo A (2002) Gamma knife radiosurgery for brain metastases: a primary therapeutic option. J Neurosurg 97:515-524. https://doi.org/10.3171/jns.2002.97.supplement _5.0515

67. Koffer P, Chan J, Rava P, Gorovets D, Ebner D, Savir G, Kinsella T, Cielo D, Hepel JT (2017) Repeat stereotactic radiosurgery for locally recurrent brain metastases. World Neurosurg 104:589-593. https://doi.org/10.1016/j.wneu.2017.04.103

68. Petrovich Z, Yu C, Giannotta SL, O’Day S, Apuzzo MLJ (2002) Survival and pattern of failure in brain metastasis treated with stereotactic gamma knife radiosurgery. J Neurosurg 97:499-506. https://doi.org/10.3171/jns.2002.97.supplement_5.0499

69. Wang XS, Ying HM, He XY, Zhou ZR, Wu YR, Hu CS (2016) Treatment of cerebral radiation necrosis with nerve growth factor: a prospective, randomized, controlled phase II study. Radiother Oncol 120:69-75. https://doi.org/10.1016/j.radonc.2016.04.027

70. Delishaj D, Ursino S, Pasqualetti F, Cristaudo A, Cosottini M, Fabrini MG, Paiar F (2017) Bevacizumab for the treatment of radiation-induced cerebral necrosis: a systematic review of the literature. J Clin Med Res 9:273-280. https://doi.org/10.14740/ jocmr2936e

71. Williamson R, Kondziolka D, Kanaan H, Lunsford LD, Flickinger JC (2008) Adverse radiation effects after radiosurgery may benefit from oral vitamin $\mathrm{E}$ and pentoxifylline therapy: a pilot study. Stereotact Funct Neurosurg 86:359-366. https://doi. org/10.1159/000163557

72. Woo E, Lam K, Yu YL, Lee PW, Huang CY (1987) Cerebral radionecrosis: is surgery necessary? J Neurol Neurosurg Psychiatry 50:1407-1414. https://doi.org/10.1136/jnnp.50.11.1407

73. Glantz MJ, Burger PC, Friedman AH, Radtke RA, Massey EW, Schold SC (1994) Treatment of radiation-induced nervous system injury with heparin and warfarin. Neurology 44:2020-2020. https ://doi.org/10.1212/wnl.44.11.2020

74. Rahmathulla G, Recinos PF, Valerio JE, Chao S, Barnett GH (2012) Laser interstitial thermal therapy for focal cerebral radiation necrosis: a case report and literature review. Stereotact Funct Neurosurg 90:192-200. https://doi.org/10.1159/000338251

75. Hong CS, Deng D, Vera A, Chiang VL (2019) Laser-interstitial thermal therapy compared to craniotomy for treatment of radiation necrosis or recurrent tumor in brain metastases failing radiosurgery. J Neurooncol 142:309-317. https://doi.org/10.1007/s1106 0-019-03097-z

76. Hernandez RN, Carminucci A, Patel P, Hargreaves EL, Danish SF (2018) Magnetic resonance-guided laser-induced thermal therapy for the treatment of progressive enhancing inflammatory reactions following stereotactic radiosurgery, or PEIRs, for metastatic brain disease. Neurosurgery 85:84-90. https://doi.org/10.1093/neuros/ nyy 220

77. Rammo R, Asmaro K, Schultz L, Scarpace L, Siddiqui S, Walbert T, Kalkanis S, Lee I (2018) The safety of magnetic resonance imaging-guided laser interstitial thermal therapy for cerebral radiation necrosis. J Neurooncol 138:609-617. https://doi. org/10.1007/s11060-018-2828-2

78. Chan AY, Tran DKT, Gill AS, Hsu FPK, Vadera S (2016) Stereotactic robot-assisted MRI-guided laser thermal ablation of 
radiation necrosis in the posterior cranial fossa: technical note. Neurosurg Focus 41:E5. https://doi.org/10.3171/2016.4.focus1622

79. Torres-Reveron J, Tomasiewicz HC, Shetty A, Amankulor NM, Chiang VL (2013) Stereotactic laser induced thermotherapy (LITT): a novel treatment for brain lesions regrowing after radiosurgery. J Neurooncol 113:495-503. https://doi.org/10.1007/ s11060-013-1142-2

80. Smith CJ, Myers CS, Chapple KM, Smith KA (2016) Long-term follow-up of 25 cases of biopsy-proven radiation necrosis or postradiation treatment effect treated with magnetic resonance-guided laser interstitial thermal therapy. Neurosurgery 79:S59-S72. https ://doi.org/10.1227/neu.0000000000001438

81. Beechar VB, Prabhu SS, Bastos D, Weinberg JS, Stafford RJ, Fuentes D, Hess KR, Rao G (2017) Volumetric response of progressing post-SRS lesions treated with laser interstitial thermal therapy. J Neurooncol 137:57-65. https://doi.org/10.1007/s1106 0-017-2694-3

82. Rammo R, Scarpace L, Nagaraja T, Lee I (2018) MR-guided laser interstitial thermal therapy in the treatment of recurrent intracranial meningiomas. Lasers Surg Med 51:245-250. https://doi. org/10.1002/lsm.23045

83. Ivan ME, Diaz RJ, Berger MH, Basil GW, Osiason DA, Plate T, Wallo A, Komotar RJ (2017) Magnetic resonance-guided laser ablation for the treatment of recurrent dural-based lesions: a series of five cases. World Neurosurg 98:162-170. https://doi. org/10.1016/j.wneu.2016.10.037

84. Ruiz A, Diaz RJ, Buttrick S, Ivan M, Desai M, Komotar RJ, Medvid R (2018) Preliminary experience on laser interstitial thermal ablation therapy in the treatment of extra-axial masses indications, imaging characterization and outcomes. Cureus. https://doi. org/10.7759/cureus. 2894

85. Tovar-Spinoza Z, Choi H (2016) Magnetic resonance-guided laser interstitial thermal therapy: report of a series of pediatric brain tumors. J Neurosurg 17:723-733. https://doi.org/10.3171/2015.11. peds 15242

86. Jethwa PR, Barrese JC, Gowda A, Shetty A, Danish SF (2012) Magnetic resonance thermometry-guided laser-induced thermal therapy for intracranial neoplasms: initial experience. Neurosurgery 71(133-144):144-145. https://doi.org/10.1227/NEU.0b013 e31826101d4

87. Dadey DY, Kamath AA, Leuthardt EC, Smyth MD (2016) Laser interstitial thermal therapy for subependymal giant cell astrocytoma: technical case report. Neurosurg Focus 41:E9. https://doi. org/10.3171/2016.7.focus 16231

88. Borghei-Razavi H, Koech H, Sharma M, Krivosheya D, Lee BS, Barnett GH, Mohammadi AM (2018) Laser interstitial thermal therapy for posterior fossa lesions: an initial experience. World Neurosurg 117:e146-e153. https://doi.org/10.1016/j. wneu.2018.05.217

89. Patel NV, Jethwa PR, Barrese JC, Hargreaves EL, Danish SF (2013) Volumetric trends associated with MRI-guided laserinduced thermal therapy (LITT) for intracranial tumors. Lasers Surg Med 45:362-369. https://doi.org/10.1002/lsm.22151

90. Barzilai O, Boriani S, Fisher CG, Sahgal A, Verlaan JJ, Gokaslan ZL, Lazary A, Bettegowda C, Rhines LD, Laufer I (2019) Essential concepts for the management of metastatic spine disease: what the surgeon should know and practice. Global spine J 9:98S-107S. https://doi.org/10.1177/2192568219830323

91. Laufer I, Iorgulescu JB, Chapman T, Lis E, Shi W, Zhang Z, Cox BW, Yamada Y, Bilsky MH (2013) Local disease control for spinal metastases following "separation surgery" and adjuvant hypofractionated or high-dose single-fraction stereotactic radiosurgery: outcome analysis in 186 patients. J Neurosurg 18:207-214. https ://doi.org/10.3171/2012.11.spine12111

92. Moussazadeh N, Laufer I, Yamada Y, Bilsky MH (2014) Separation surgery for spinal metastases: effect of spinal radiosurgery on surgical treatment goals. Cancer Control 21:168-174. https://doi. org/10.1177/107327481402100210

93. Ahrar K, Stafford RJ (2011) Magnetic resonance imaging-guided laser ablation of bone tumors. Techn Vasc Interv Radiol 14:177182. https://doi.org/10.1053/j.tvir.2011.02.010

94. Tatsui CE, Stafford RJ, Li J, Sellin JN, Amini B, Rao G, Suki D, Ghia AJ, Brown P, Lee S-H, Cowles CE, Weinberg JS, Rhines LD (2015) Utilization of laser interstitial thermotherapy guided by real-time thermal MRI as an alternative to separation surgery in the management of spinal metastasis. J Neurosurg 23:400-411. https://doi.org/10.3171/2015.2.spine141185

95. Laufer I, Rubin DG, Lis E, Cox BW, Stubblefield MD, Yamada Y, Bilsky MH (2013) The NOMS framework: approach to the treatment of spinal metastatic tumors. Oncologist 18:744-751. https://doi.org/10.1634/theoncologist.2012-0293

96. Tatsui CE, Nascimento CNG, Suki D, Amini B, Li J, Ghia AJ, Thomas JG, Stafford RJ, Rhines LD, Cata JP, Kumar AJ, Rao G (2017) Image guidance based on MRI for spinal interstitial laser thermotherapy: technical aspects and accuracy. J Neurosurg 26:605-612. https://doi.org/10.3171/2016.9.spine16475

Publisher's Note Springer Nature remains neutral with regard to jurisdictional claims in published maps and institutional affiliations. 